\title{
Natureza, sentidos e integração: caso de estudo do centro Helen Keller
}

\author{
(Nature, senses and inclusion: the Helen Keller centre case study) \\ Maria ROMEIRAS AMADO \\ UIDEF - Unidade de Investigação e Desenvolvimento em Educação e Formação \\ Instituto de Educação da Universidade de Lisboa
}

\begin{abstract}
RESUMO: O foco do meu presente estudo incide no Centro Helen Keller, uma escola privada portuguesa fundada em 1955 com o objetivo de integrar alunos com diversas características de visão, nomeadamente crianças cegas, com baixa visão e normovisuais. Integrada num parque natural de Lisboa com 1012 hectares, esta escola dispõe de uma situação privilegiada para assimilar a natureza na sua potência de educação e convívio a tão diverso corpo discente. Do ponto de vista neurológico, a diversidade sensorial presente é assim desenvolvida pela variedade de estímulos existentes na natureza envolvente, disponíveis para aproveitamento pedagógico e socializante. Como fazer da diversidade de sentidos um ponto de socialização e de aprendizagem é o meu principal interesse, para tal acompanhando a história e circunstâncias desta escola integrada, de inspiração Freinet, até aos nossos dias, em que valores como a Ecologia são parte do seu quotidiano.
\end{abstract}

PALAVRAS-CHAVE: Natureza; Sentidos; Educação Integrada; História da Deficiência; Cegueira.

ABSTRACT: This study focuses on the Helen Keller Center, a private Portuguese school founded in 1955 for the purpose of integrating students with different levels of vision: blindness, visual impairment or sighted. Located in Lisbon on 2500 acres of natural park, this school boasts a privileged situation, allowing for the natural environment to be an integral part of its pedagogical and social structure aimed at a widely diverse student body. From a neurological point of view, the spectrum of sensory experiences in these natural surroundings fosters balanced creative development through the different stimuli used for pedagogical purposes. Therefore, my main interest is to question the relationship between the discovery of nature and both the socialization and the sensorial learning processes. The history and developmental circumstances of this Freinet inspired school will bring us to the present day, when ecology has become part of the school's daily routine.

KEYWORDS: Nature; Senses; Integrated Education; Disability History; Blindness. 


\section{Introdução}

Vincularei os dados necessários à minha reflexão sobre a importância da utilização dos conceitos subjacentes ao destaque da natureza em meio pedagógico, ao século XVIII, quando a par do desenvolvimento das instituições escolares, se desenvolveu um renovado apreço pela natureza e pela saúde. Ideais que ficaram bem patentes nas reflexões e escritos de Rousseau, em que a aliança entre natureza e educação constituiu uma renovada proposta pedagógica: neles se destacavam a importância do ar livre, de uma vida higiénica e saudável com bastante interação com o exterior, e a criação de permanentes e diversos estímulos do corpo e da voz que, segundo este autor, eram os primordiais para bons resultados no desenvolvimento da mente. ${ }^{1}$ Vários pedagogos e filósofos seguiram e desenvolveram as suas teorias sobre o binómio natureza-educação, como por exemplo 0 conceito de natureza viva e polissistemica de Merleau-Ponty, de onde se poderiam inferir muitas reflexões sobre integridade e complementaridade, semelhanças e diversidades no mundo natural? .

Há, assim, nas palavras-chave escolhidas para este trabalho, duas de maior grandeza, no sentido em que são as dinamizadoras do seu gesto reflexivo: os conceitos de Sentidos e de Natureza. Destaco ainda nesta breve reflexão inicial o contexto particular de que 0 contacto pedagógico com a natureza se reveste neste caso específico, dada a miscigenação, no Centro Helen Keller, de alunos com diversas características sensoriais.

O caso de estudo assumido é assim bem ilustrativo da potência destes dois conceitos como motores num projeto pedagógico integrador de crianças aparentemente vinculadas à diferença, tornando-se eixos de aproximação quer do ponto de vista académico, quer do ponto de vista de uma socialização corporativa que se pretendeu universal e diversa no corpo discente, bem como na comunidade escolar e social envolvente. $\mathrm{O}$ uso e a exploração pedagógica da natureza foram assim determinantes em projetos escolares como o que se aborda, dada a sua potência de participação diversa e de experimentalismo do corpo por parte dos seus vários sentidos, assumindo aproximações atentas e parcelares de uma realidade a explorar por um grupo tão diverso quanto complementar de alunos, adaptando as linhas pedagógicas tradicionais à sua especificidade sensorial, social e cooperativa.

Para contextualizar o projeto em causa, e depois de uma breve abordagem à relevância da natureza na História da Educação, segue-se, num segundo tempo, a mesma reflexão em relação aos sentidos. Em terceiro lugar, desenvolvo um breve recordar da História da Educação de Cegos e Amblíopes por contraponto à Educação dita de alunos normais, focando com mais detalhe o caso Português.

\footnotetext{
${ }^{1}$ Carmen Lucia Soares. "Uma educação pela natureza: o método de educação física de Georges Hébert», Revista Brasileira de Ciências do Esporte, no. 37 (2015): 151-157.

${ }^{2}$ Maria Isabel Brandão de Souza Mendes, Terezinha Petrucia da Nóbrega, «Corpo, natureza e cultura: contribuições para a educação", Revista Brasileira de Educação, no. 27 (Set /Out /Nov /Dez 2004): 125-136. Online em http://www.redalyc.org/html/275/27502709/ (22 de Outubro de 2018).
} 
Uma vez feita a localização do tema principal, situarei então o meu caso de estudo, o Centro Helen Keller ${ }^{3}$ no seu lugar histórico e sociológico do Portugal dos anos 50 do século XX. Finalmente, descreverei brevemente a evolução desta escola desde a sua fundação passando por várias mudanças de instalações e consequentes condições de contato com o meio exterior - até à aquisição das suas instalações definitivas no Parque Natural de Monsanto e passarei à leitura do seu aproveitamento destas novas instalações, rodeadas pela natureza e com incentivos estruturados nesse tema para levar a cabo de maneira eficiente os seus propósitos de integração e socialização de alunos sensorialmente diversos.

Por último, mas não menos relevante para a socialização de todos os alunos, abordarei a questão da divulgação dos trabalhos: numa escola herdeira das técnicas de Freinet não poderia faltar o hábito da correspondência ou da imprensa, chegando até hoje, orientada pelo Movimento da Escola Moderna, com o espírito de cooperativismo e partilha que continuam refletidos nas suas revistas, redes sociais e eventos comunitários.

A conclusão deste breve percurso pelas possibilidades pedagógicas do encontro dos sentidos de alunos diversos com a potencialidade da natureza envolvente a um meio escolar conduz-nos a novas interrogações acerca dessa integração de alunos diversos no meio da natureza, um meio de novidades, usufruto e aprendizagem de todos e para todos, em que a criatividade se impõe e a ligação da natureza humana ao meio natural é uma realidade de desenvolvimento pedagógico ativo. É desse gesto de produtividade pedagógica e desse contato sensorial privilegiado e individualmente rico que cresce o sentir cooperativo e socializante da comunidade escolar, potência integradora a estudar neste capítulo tão específico da História da Educação.

\section{Relevância da natureza na história da educação}

No final do século XIX a educação pela Natureza teve um crescimento significativo no mundo Ocidental. A teorização de Rousseau (1712 - 1778) sobre o espaço exterior e a natureza tinha proporcionado grande abertura a experimentalismos pedagógicos a partir do século XVIII. A natureza passara assim de meio hostil a aliada do gesto pedagógico. E enquanto as instituições escolares se iam firmando como nova matriz de gestão e orientação da infância ${ }^{4}$, este inovador gesto pedagógico, sob o binómio natureza-educação, ia progressivamente dando os seus frutos em várias linhas pedagógicas: «Defendendo o jogo, a psicomotricidade e a jardinagem como atividades a serem incentivadas/praticadas na escola, Froebel alertou para a integração escola-natureza e, portanto, para a necessidade desta conter espaços livres utilizáveis pelos estudantes». ${ }^{5}$

\footnotetext{
${ }^{3}$ Dados reunidos ao abrigo de INOVAR, Projeto PTDC/MHC-CED/0893/2014 da Fundação para a Ciência e Tecnologia.

${ }^{4}$ Thomas Popkewitz, «Foreword: Hopes of Inclusion/Recognition and Productions of Difference», in The Child in The World/ The World in The Child. Education and the Configuration of a Universal, Modern, and Globalized Childhood, ed. Marianne Bloch, al. (Nova Iorque: Palgrave MacMillan, 2006), ix.

${ }^{5}$ Gleice Azambuja Elali, «O ambiente da escola - 0 ambiente na escola: uma discussão sobre a relação escolanatureza em educação infantil», Estudos de Psicologia 8, no. 2 (2003): 311.
} 
Numa época de desenvolvimento científico, as matérias ensinadas nas escolas públicas e nos colégios privados necessitavam de uma materialidade de base para suporte a estas novas formas de aprendizagem. Quer as teorias de Rousseau quer o crescente higienismo em que se apoiaram as instituições escolares em desenvolvimento pelo século XVIII e XIX, permitiram que a sala de aulas saísse de si mesma enquanto espaço confinado e se envolvesse com a natureza de diversas formas: ou através de aulas de exterior com observações e recolhas de materiais e experiências, ou também através da implementação de museus escolares e laboratórios, gestos pedagógicos que veriam o seu espaço programático definitivamente implementado no início do século XX, com o desenvolvimento sistemático das visitas de campo e visitas de estudo a museus e instituições científicas ${ }^{6}$.

Por outro lado, desde meados do século XIX que a arquitetura escolar se encarregava de trazer à sala de aula elementos da natureza como a luz, pelas novas janelas rasgadas e intervenientes no espaço e na relação do corpo com o espaço escolar, prevenindo doenças, criando minúcia na observação, permitindo uma outra forma de observar e de ser observado ${ }^{7}$. Seguir-se-ia, nos anos 20 e 30 do século XX, um movimento de atividades de lazer ligadas a novas formas de pedagogia baseadas em observação direta e experimentação. $O$ objetivo era de identificar, classificar e experimentar utilizando materiais recolhidos na natureza, incentivando e aprofundando o seu estudo e conhecimento através de um contacto direto com a sua materialidade.

A educação pela natureza espalhou-se assim por vários níveis de escolaridade, sendo mesmo difundida nos anos iniciais, usando os conhecimentos sensoriais mais simples e diretos para a recolha e usufruto de matérias naturais, mote para trabalhos artísticos e pedagógicos diversificados, adaptados aos níveis de escolaridade em causa. Associações foram igualmente desenvolvidas, como é o caso do Movimento Escotista em 1908', que incentivou o contacto dos jovens com a natureza e a aprendizagem direta destes sobre a mesma, em paralelo com a instituição escolar.

A preocupação com a educação física associou-se ainda a esta nova perspetiva pedagógica. $O$ higienismo implicava, também, esse contacto recreativo e pedagógico com 0 exterior. A reter alguns detalhes como a preocupação com exercícios de motricidade apurada nos primeiros anos de escolaridade, a incidência da relação com a natureza, em particular por parte das turmas de alunos do sexo masculino, nomeadamente em atividades que desenvolvessem a termorregulação, a força e o equilíbrio. ${ }^{9}$ No que toca aos alunos com diferenças sensoriais - caso das primeiras escolas para alunos cegos - a perspetiva de orientação e mobilidade era bastante incentivada em aulas de exterior e a postura e

\footnotetext{
${ }^{6}$ Inês Félix, «Herança e Cidadania: Visitas de Estudo, Excursões Escolares e Educação Estética na formação dos jovens escolares portugueses (1894 - 1960)» (Tese de mestrado, Universidade de Lisboa, 2010), 49-51.

${ }^{7}$ Catherine Burke. «Light in the History of Schooling», in Materialities of Schooling. Design. Technology. Objects. Routines, ed. Martin Lawn, lan Grosvenor (Oxford: Symposium Books, 2005), 125-143.

${ }^{8}$ History | Scouts, https://scouts.org.uk/about-us/heritage/ (16 de Outubro de 2018).

${ }_{9}^{9}$ Anthony Pellegrini, Peter Smith. «Physical Activity Play: The Nature and Function of a Neglected Aspect of Play», Child Development 69, no. 3 (1998): 577-598.
} 
combate aos maneirismos eram trabalhados nas aulas de ginástica que era uma aliada da normalização escolar mesmo dentro dos quadros da diferença.

Foi também sendo desenvolvida uma relação de curiosidade científica e de responsabilidade pela natureza, encarada como fonte de informação sobre o mundo que rodeava a escola e no qual se enquadrava o aluno, com materialidade disponível para estudos e trabalhos em várias matérias e possibilidade de participação cívica ativa e responsável no contato e intervenção com o meio ambiente. Socialmente, certos eventos, como o Dia da Árvore, passaram a ser celebrados com espírito laico e de intervenção cívica desde o final do século XIX e essas comemorações de renovação, de inspiração maçónica, foram sendo adotadas pedagogicamente - no caso português sobretudo depois da implantação da República ${ }^{10}$.

Em Portugal, a aproximação à natureza como ponto de enriquecimento pedagógico tinha atingido um ponto de relevo com a reforma de 1894-1895 de Jaime Moniz. Como afirma Inês Félix no seu estudo sobre a educação no exterior, com esta reforma «as excursões escolares tomam parte ao figurar no diploma de 1895, associando-se desde logo a um dos objetivos da disciplina de história: o desenvolvimento do amor à pátria e à nacionalidade " ${ }^{11}$ o que associa o lado nacionalista ao lado pedagógico da exploração do mundo fora da escola e à sua aproximação nas temáticas escolares.

Temos então, desde finais do século XVIII, e em paralelo com o desenvolvimento da própria instituição escolar, a natureza presente na perspetiva da saúde, na perspetiva patrimonial, na responsabilidade e dever cívico e no conhecimento científico. Esta relação estabeleceu-se com fundamentos teóricos, mas também pragmáticos, exigindo uma aproximação da materialidade e dos espaços, implicando gestão de espaços dentro da escola - jardins, laboratórios - ou fora da escola em modo de visitas de campo diversas e aulas de exterior.

É, finalmente, de realçar a importância da natureza enquanto tema para trabalhos artísticos e literários, ou seja, como uma matriz inspiradora, uma janela sobre o mundo, para seu melhor conhecimento, compreensão e utilização. Atualmente a educação ambiental é incontornável nos sistemas educativos ${ }^{12}$, mesmo os sensorialmente adaptados como no caso de estudo que escolhi.

\footnotetext{
${ }^{10}$ Alberto Filipe de Abreu Araújo, Joaquim Machado de Araújo, «Dos Ideais e do Simbolismo da Festa da Árvore na I República» in Rituais, Espaços \& Patrimónios Escolares. IX Congresso Luso-Brasileiro de História da Educação (Livro do Congresso), org. Maria João Mogarro, Maria Teresa Santos Cunha (Lisboa: Instituto de Educação da Universidade de Lisboa, 2012), 3247-3251. Online em https://repositorio.ucp.pt/bitstream/10400.14/13037/1/ Dos $\% 20$ Ideais $\% 20$ do $\% 20$ Simbolismo $\% 20$ da $\% 20$ Festa $\% 20$ da $\% 20 \%$ C3 $\% 81$ rvore $\% 20$ na $\% 201 \% 20$ rep\%C3\%BAblica.pdf (18 de Outubro de 2012).

11 Inês Félix, "Herança e Cidadania», 9.

12 Philippe Pomier Layrargues, "Muito Além da Natureza: Educação Ambiental e Reprodução Social», in Pensamento complexo, dialética e educação ambiental, org. Carlos Frederico Bernardo Loureiro, Philippe Pomier Layargues, Ronaldo Souza de Castro (São Paulo: Cortez Editora, 2006), 72-103.
} 


\section{Os sentidos e a educação - neurodiversidade e integração}

De acordo com dados da Organização Mundial de Saúde, cerca de 285 milhões de pessoas, adultos e crianças, em todo o mundo, são cegos ou têm deficiências da visão. Percorrer o exterior é desafiador para os deficientes visuais e a existência de rotas Braille ou jardins sensoriais oferecem oportunidades sustentáveis para mobilidade aumentada e acesso à natureza. ${ }^{13}$

Conforme abordei no ponto anterior, a Natureza foi sempre aliada da Escola, pelo que a educação teve sempre uma relação muito direta e criativa com os sentidos. Sobretudo em escolas como a que abordamos neste estudo, em que a ausência ou diminuição de um dos principais sentidos de acesso à informação exterior é um dado adquirido, julgo ser de relevo uma abordagem à possibilidade de contacto neuro-sensorial com essa imensa fonte de informação e materialidade que é oferecida pela Natureza, alimentando programas nas escolas - regulares ou adaptadas - e permitindo aos alunos um conhecimento prático e direto de muitas matérias de estudo e consequentes processos de criatividade na aprendizagem.

Como tal, e dado que a informação que nos chega pelos sentidos é diversa e de diversas intensidades, é de registar, em primeiro lugar, que a pedagogia adaptada utiliza técnicas que não fazem predominar uma ou outra via de comunicação, mas jogam com a neuroplasticidade dos alunos como forma de complementar informações adquiridas pelo meio envolvente.

A visão é o sentido tradicionalmente de uso mais imediato e generalista - como teorizado por Aristóteles em função do seu contributo para o conhecimento - embora se tenha chegado à conclusão que não é o mais preciso ou fiável, conforme questões aturadamente colocadas por Berkeley (1685-1753) e Molineux (1656-1698) ${ }^{14}$. Assim, é necessário contar com imprecisões, consciencializá-las, e também assumir pedagogias alternativas, nomeadamente a descrição verbal do que é passível de visualização, bem como a utilização dos outros quatro sentidos como reforço de informação, ou mesmo de algumas próteses úteis para as variações da capacidade de visão, quando esta é parcialmente possível, como sejam os óculos ou as lupas. Já na segunda metade do século XX a escola abriria as suas portas a uma nova revolução de ajudas técnicas, com novos meios de reforço ou apoio às deficiências de visão, por exemplo, ampliadores eletrónicos ou software de leitura de voz para o computador, ajudas essas que equalizariam o acesso à informação na sala de aula e mesmo no mercado de trabalho.

É preciso ter igualmente em conta que, por vezes, a utilização de duplicação de informação é utilizada pedagogicamente para um maior efeito de mnemónica em situações de aprendizagem, mesmo que não haja necessidade de compensação sensorial. E se a visão, numa situação sensorial regular, é o sentido que mais imediatamente capta a

${ }^{13}$ Nature for the blind, http://www.naturefortheblind.com/home (23 de Agosto de 2018). Tradução inglês-português da autora.

${ }^{14}$ Donald Hoffman, Visual Intelligence. How We Create What We See (Nova lorque: W.W. Norton \& Company, 1998). 
informação disponível, independentemente da sua distância e quantidade, recebendo ainda dados sobre a sua aparência, aparente textura, aparente cor, aparente forma e outros dados como a sua posição relativa em relação a outros objetos ou planos, em muito é acrescida e enriquecida em acuidade por outras inferências sensoriais de reforço e complemento de informação. No caso das crianças cegas, o desenvolvimento das áreas corticais occipitais enriquece a plasticidade multimodal. 0 que significa, que não é por não haver o sentido da visão ativo que se desenvolvem mais os da audição ou do tato, mas apenas que a disponibilidade para o seu desenvolvimento se encontra mais ativada e que o incentivo ao uso desses outros sentidos certamente encontra um reflexo positivo na sua utilização e desenvolvimento.

É, como tal, de grande relevância, a participação de situações de parcialidade sensorial em experimentações e alternativas com utilização de outros sentidos, permitindo o seu maior desenvolvimento neurológico e uma maior acuidade da sua potência ${ }^{15}$. Não como compensação, mas como um empoderamento de per se. E nestes casos, o contacto com a natureza, pela sua riqueza e diversidade de experiências, é um excelente caminho pedagógico para um equilíbrio dos sentidos existentes com o conhecimento do mundo exterior, tão rico em estímulos e tão potente em experiências.

Deste modo, se da natureza nos chegam informações sensoriais que podem alimentar os cinco sentidos, permitindo a variedade e o enriquecimento das conclusões pelo seu cruzamento e pela eventual compensação que a riqueza informativa providencia, é nela que encontramos um ponto de integração e nivelamento bastante eficiente e compensador da existência de diferentes competências no corpus diverso de alunos em que o nosso estudo incide. Porque a riqueza de estímulos reforça a produtividade do trabalho académico e potencia a democratização de acesso à informação de alunos com várias características ${ }^{16}$.

Assim, os sons, cheiros e texturas aportam dados que são úteis para a aprendizagem de todos os alunos. Os alunos com visão usufruem de toda a potência da informação que a natureza lhes proporciona. Os alunos com baixa visão desenvolvem através de todos os sentidos, com menos intensidade pela visão, com mais intensidade pelo tato, da informação a usufruir e recolher para uso no exterior ou em sala de aula. Os alunos cegos, por sua vez, utilizam os outros quatro sentidos para atingir as mesmas conclusões que os seus colegas, contando com o complemento da descrição, pelos colegas ou pelos professores, dos dados que a visão proporciona, como é o caso da cor ou mesmo da distância, por exemplo. Seja como for, numa turma mista, os referentes sensoriais são de grande diversidade de usos e passíveis de criar um ambiente socializante e de colaboração e troca de

\footnotetext{
${ }^{15}$ Daniel Goldreich, Ingrid Kanics, «Tactile Acuity is Enhanced in Blindness», Journal of Neuroscience 23, no. 8 (2003): 3439-3445

${ }^{16}$ Chapter Three - Enhancing Vision Through Touch, https://nfb.org/images/nfb/publications/books/integratingprint-braille/integratingprintandbraillechapter3.html (18 de Outubro de 2018).
} 
ideias e de pontos de vista, contribuindo para o conhecimento de uma realidade passível de uma diversidade de abordagens e processada pelo córtex por vários estímulos. ${ }^{17}$

Na medida em que a aproximação da natureza humana dos alunos de diversas características sensoriais à natureza na sua riqueza espacial, da sua fauna, da flora espontânea e cultivada, dos seus sons, aromas e texturas, proporciona esse potencial científico e criativo enriquecedor das aulas e socialmente cativante irei então debruçar-me sobre os movimentos escolares que desenvolveram essa técnica pedagógica de integração sensorial.

\section{A educação de cegos e amblíopes: breve enquadramento}

Que la différence soit à la lettre «inexplicable», il n'y a pas lieu de s'en étonner. La différence s'explique, mais précisément elle tend à s'annuler dans le système ou elle s'explique. Ce que signifie seulement que la différence est essentiellement impliquée, que l'être de la différence est l'implication. S'expliquer, pour elle, c'est s'annuler, conjurer l'inégalité que la constitue. ${ }^{18}$

Na Modernidade, os sistemas de escolaridade institucional foram divulgados pela sociedade ocidental e surgiram, em paralelo, as primeiras escolas para cegos, sendo a inicial o Instituto Nacional para os Jovens Cegos, em Paris, em 1785, fundado por Valentin Haüy (1745-1822) onde viria a estudar, a adaptar a sonografia Barbier ao sistema inédito que adotou o seu nome (1829), e a ser professor, a grande referência Louis Braille (1809$1852)^{19}$. A escolaridade evoluía assim apoiando pedagogicamente a diversidade dos seus alunos e criando meios, técnicas e tecnologias para a sua implicação num gesto simultaneamente educativo e socializante.

O britânico John Alston afirma a esse respeito: «It seems strange that there should exist a doubt in the mind of any one of the expediency of educating the blind; or, that it should be supposed enough has been done for them, when their corporal wants have been supplied. They are rational and immortal beings, and capable of all the enjoyment which others feel from the cultivation of their moral and intellectual powers». ${ }^{20}$

Deste modo, a par da criação e generalização das escolas de crianças normovisuais, foram sendo criadas algumas escolas adaptadas para crianças com diversidades físicas ou sensoriais que já se podiam considerar como não sendo parte do antigo regime asilar.

\footnotetext{
${ }^{17}$ Semir Zeki, Splendours and Miseries of the Brain: Love, Creativity, and the Quest for Human Happiness (Oxford: Wiley-Blackwell, 2009), 91.

18 "Que a diferença seja, à letra, inexplicável, nada tem de espantoso ou de estranho. A diferença explica-se, mas precisamente tende a anular-se no sistema onde se explica. $\mathrm{O}$ que significa unicamente que a diferença está essencialmente implicada, que a essência da diferença é a implicação. Explicar-se, para ela, é anulá-la, conjurar a diferença que a constitui.» Tradução da autora a partir de Jacques Deleuze, Différence et Répétition, (Paris: PUF, 1993), 293.

${ }^{19}$ Zina Weygand, Vivre Sans Voir. Les Aveugles dans la Société Française, du Moyen Âge au siècle de Louis Braille (Paris: Creaphis, 2003).

${ }_{20}$ «Parece estranho que haja alguma dúvida na mente de alguém sobre a possibilidade de educar os cegos; ou que se haja já feito o suficiente quando as suas necessidades corporais forem supridas." Tradução da autora a partir de John Alston, Statements of the education, employment, and internal arrangements, adopted at the Asylum for the Blind, Glasgow (Glasgow: Asylum for the Blind, 1836).
} 
Mencionámos, em particular, o caso da educação de crianças cegas, ou seja, a fundação em Paris, do Institut National des Jeunes Aveugles, em $1785^{21}$, a primeira escola com intenções de educar e, ao contrário dos asilos que geriam os seus instituídos durante um tempo indeterminado, permitir a saída, no final da aprendizagem e integração, dos seus alunos, com um relativo nível de autonomia e possibilidades de desenvolver uma vida pessoal e profissional o mais aproximada possível à dos seus colegas normovisuais.

Para tal era promovido o ensino de matérias diversas: catecismo, leitura, escrita relevada, exercícios de memória, gramática, ortografia, composição, literatura, geografia, história, matemática, história natural, música, entre outras disciplinas. Estas eram as bases de aprendizagem do Instituto Nacional para os Jovens Cegos de Paris, a partir do qual se fundamentaram as outras primeiras escolas do mundo ocidental a preocuparem-se com a integração de alunos cegos na sociedade moderna, incluindo a primeira escola portuguesa, o Asilo-escola António Feliciano de Castilho, fundada em 1888.

Nestas instituições, a diferença propôs-se diluir a sua essência na normalização pela educação. No caso dos cegos e dos alunos de baixa visão, a essência comunicacional - a fala - e o registo principal das aulas e das orientações - a memória - eram primordiais e muito desenvolvidos. $O$ trabalho aturado de criação de meios de produção de outro tipo de informação como a escrita relevada - em Braille ou noutros sistemas alternativos, como os anglo-saxónicos Moon e Gall - apoiava a fluência das aulas e permitia a interação destes alunos com outros alunos de outras escolas, de outros países, de outras caraterísticas, de outros meios sociais.

Assim, a diferença sensorial destes alunos não provocava mais que uma vontade de gerar oportunidades e, por isso mesmo, era muito mais uma integração que uma segregação. E foi a partir da instituição de Paris que as instituições congéneres foram surgindo pelo mundo ocidental.

\begin{abstract}
Pour la seconde fois Son Excelence M. le Ministre de l'Intérieur m'a déllégué ses pouvoirs pour présider la solemnité qui couronne l'année scolaire à l'Institution des Jeunes Aveugles. Je m'en aplaudis; car, depuis longtemps, cette institution, si justement célèbre, a mes plus tendres sympathies. Eh! Comment pourrait-il être autrement? Existe-t-il un sujet plus digne d'intêret que celui de l'éducation de nos chers enfants?

N'est-ce-pas une des gloires de nôtre pays que d'avoir le premier institué l'enseignement des Jeunes Aveugles? Si l'honneur de la création appartient au siècle dernier, le nôtre peut, du moins, s'enorgueillir d'avoir continue, en la fécondant, l'oeuvre commencé par l'illustre Valentin Haüy. L'exemple donnée par la France a été suivi par les autres peuples et les grandes villes de l'ancien et du nouveau monde se sont dotées à l'envi d'établissements semblables à celui que Paris avait fondé. ${ }^{22}$
\end{abstract}

\footnotetext{
${ }^{21}$ Maria Romeiras Amado, «Hide and Seek: normality issues and global discourses on blind school modern projects (late 18th - 19th centuries)" (Tese de doutoramento, Universidade de Lisboa, 2012).

${ }_{22}^{2}$ «Pela segunda vez, Sua Excelência, o Senhor Ministro do Interior delegou-me os seus poderes para presidir à solenidade que coroa o ano escolar na Instituição dos Jovens Cegos. Aplaudo, porque, há bastante tempo que esta instituição tão justamente celebrada, tem a minha simpatia. E como poderia ser de outra forma? Existirá algum assunto mais digno de interesse que 0 da educação das nossas queridas crianças? Não é uma das glórias do nosso país ter instituído o ensino de Jovens Cegos? Se a honra desta criação pertence ao século passado, o nosso pode ao menos continuar a orgulhar-se desenvolvendo a obra começada por Valentin Haüy.
} 
Este grande passo para a integração implicou uma adaptação de materialidade que apoiasse o estudo através de sentidos que não a visão em exclusivo. Assim, e apesar de, nos asilos e na educação em casa, já haver por vezes recursos a materiais que valorizavam a aprendizagem pelo tato, as escolas vieram trazer meios, possibilidades e caminhos de uma nova materialidade específica que foi sendo desenvolvida progressivamente. Além do contacto com os materiais originais: caso de animais empalhados, de folhas ou de rochas nas aulas de ciências, outras dimensões eram ultrapassadas com o apoio de reproduções de imagens em relevo ou em três dimensões. Este fator é particularmente relevante no que diz respeito ao estudo da Natureza, com os globos terrestes em relevo e legendados em Braille ou sistema equivalente e nos sistemas cartográficos relevados, também adequadamente legendados de forma ampliada ou relevada.

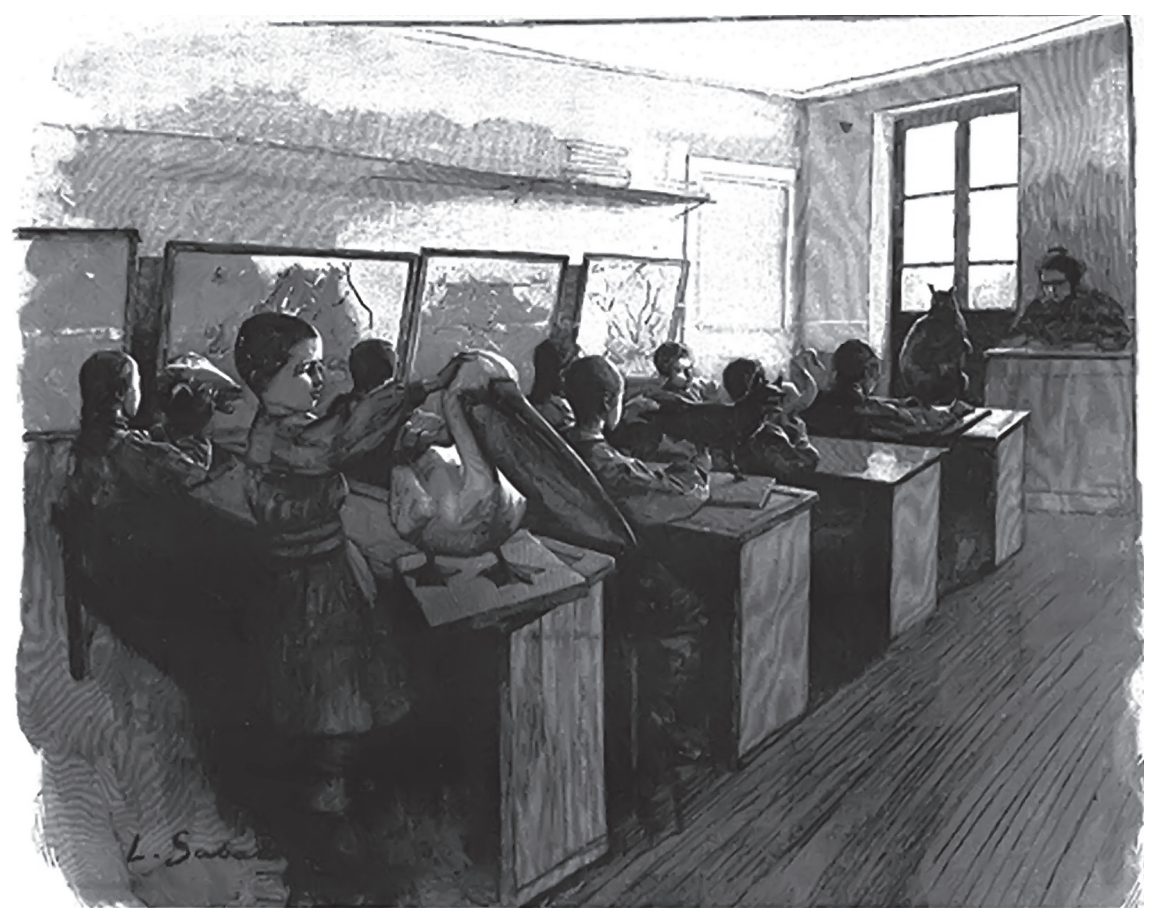

Figura 1. Gravura da Escola Braille de Paris representando uma aula prática para raparigas cegas, em que tocam materiais tridimensionais que estão distribuídos pelas suas mesas de trabalho, tais como animais empalhados. Veem-se ainda alguns mapas relevados colocados à altura das mãos nas paredes da sala de aula.

O exemplo dado pela França foi seguido pelos outros povos e as grandes cidades do antigo e do novo mundo predispuseram-se a estabelecer instituições semelhantes ao fundado em Paris.» Tradução da autora a partir de Joseph Guadet, L'Institut des Jeunes Aveugles de Paris. Son histoire et ses procédés d'enseignement (Paris: E. Thunot et C.e, 1849), 21-22. 
Evidentemente que, nos casos de algumas famílias mais abastadas, essas mesmas crianças com deficiências da visão tinham desde cedo tutores - mais tarde secretários dando azo a muito espanto e muita escrita sobre os seus dotes auditivos e de memória, desenvolvidos desde a mais tenra infância, como nos descreve Diderot na sua Carta Sobre os Cegos Para Uso das Pessoas que Veem ${ }^{23}$ e também Joseph Guadet nas suas reflexões pedagógicas sobre as crianças cegas:

l'aveugle de Puyseaux avait appris à lire à son fils avec des caractères en relief mobiles.- Mademoiselle De Salignac faisait usage aussi de caractères en relief mobiles.- (...) Mademoiselle Paradis enfin, avait appris à épeler sur des cartes avec des épingles. Elle possédait une petite presse et des caractères mobiles au moyen desquels elle imprimait sur un papier des phrases qu'elle composait à la manière des imprimeurs, et elle entretenait ainsi correspondance avec ses amis. ${ }^{24}$

A adicionar a estas condições o imaginário do iluminismo, percecionamos facilmente que casos como António Feliciano de Castilho (1800-1875) ${ }^{25}$ eram exceções de grande destaque social. Mas precisamente porque havia esse ideal e esse imaginário iluminista, a educação esteve sempre associada a um sentido de civilidade e de utilidade dos deficientes visuais. Por outro lado, o sensorialismo procurou, no desenvolvimento dos outros sentidos, idênticas possibilidades de comunicação, ou seja, um investimento pedagógico normalizador.

Desta forma, quer em sistema de educação por tutoria, quer nas primeiras escolas para cegos e amblíopes como as escolas de Paris (1785), de Liverpool (1790), de Milão (1836), do Rio de Janeiro (1854), de Lisboa (1888), os programas eram de carácter teórico, mas também prático, variando as disciplinas consoante a especialização dos professores disponíveis ou o programa mais ou menos ambicioso. Regra geral, nas escolas ocidentais destinadas a alunos cegos, o programa curricular constava das acima referidas matérias gerais, idênticas às das escolas tradicionais: o idioma nacional, a História, a Geografia, apenas diferindo na inclusão do Braille ou de outro sistema adotado para escrita em rele$\mathrm{vo}^{26}$, entre outras matérias. ${ }^{27}$

Do ponto de vista mais pragmático, o ensino da música era o principal, quer em termos teóricos quer em termos práticos, de canto e instrumental. Mas em todas as escolas de que consultei documentação, encontrei sempre referência também à ginástica, associada ao movimento higienista, como parte importante da educação dos alunos cegos, até pelas

\footnotetext{
${ }^{23}$ Denis Diderot, Carta Sobre os Cegos Para Uso Daqueles que Veem (Lisboa: Passagens, 2007).

${ }^{24}$ "O cego de Puyseaux tinha ensinado o seu filho a ler com caracteres móveis em relevo. Mademoiselle de Salignac usava igualmente caracteres em relevo móveis. Mademoiselle Paradis, enfim, tinha aprendido a picotar sobre cartões com alfinetes. Tinha uma pequena impressora e caracteres móveis através dos quais imprimia sobre um papel frases que compunha ao modo dos impressores e assim se correspondia com os seus amigos". Tradução da autora a partir de Joseph Guadet, L'Institut des Jeunes Aveugles de Paris, 13.

${ }^{25}$ Justino de Magalhães, «António Feliciano de Castilho», in Dicionário de Educadores Portugueses, ed. António Nóvoa (Porto: Edições Asa, 2003), 198 e seguintes.

${ }^{26}$ Maria Romeiras Amado, «Escritos em Branco. Rupturas da ciência e da pedagogia no Portugal Oitocentista: 0 ensino para cegos no Asilo-escola António Feliciano de Castilho (1888-1930)" (Tese de mestrado, Universidade de Lisboa, 2007).

${ }^{27}$ Joseph Guadet, L'Institut des Jeunes Aveugles de Paris.
} 
questões que implicavam correções de postura, orientação e mobilidade. Assim, as aulas ao ar livre eram parte do dia-a-dia destes alunos do século XIX e continuarão a ser de grande importância ao longo do século XX como seguidamente descreverei.

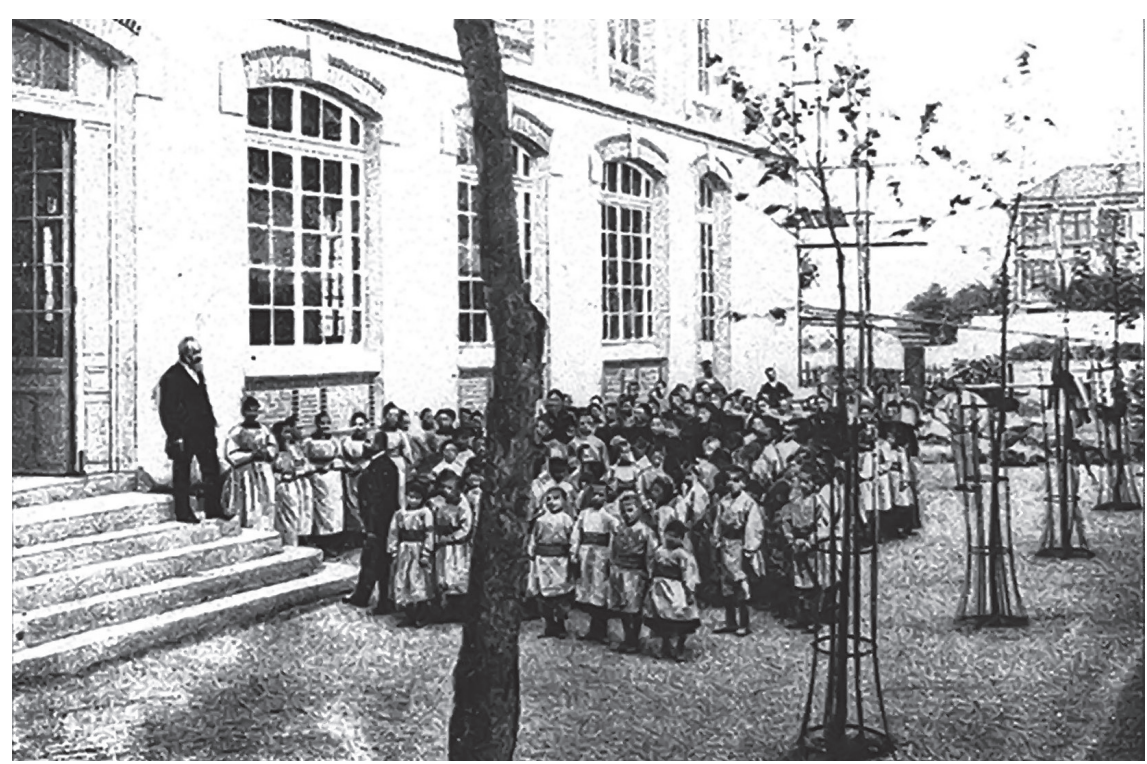

Figura 2. Fotografia de alunos e trabalhadores da Escola Louis Braille de Paris em uniformes de ginástica, no exterior do edifício da escola, tal como apresentado e descrito em Monographie de l'école Louis Braille.

Em suma, não só a educação se adaptava a circunstâncias sensoriais diversas em instituições de ensino especializadas, como a natureza desde cedo fazia parte do seu currículo, sob a forma de materiais adaptados e mesmo sob a forma de experimentação do ambiente de fora da escola em exercícios físicos tendentes à boa integração e postura das crianças cegas perante uma sociedade que inicialmente lhes era observadora e avaliadora de capacidades. Em todo o caso, a natureza estava já presente, desde 0 início, quer nos interesses académicos, quer na materialidade escolar adaptada, quer ainda nas atividades e precauções higienistas, nas primeiras escolas para crianças cegas do mundo ocidental.

\section{Portugal: das escolas para cegos ao ensino integrado}

The governing of the child was a response to the uncertainty of modernity but also embodies a cultural strategy that expressed fears about maintaining the qualities of a civilized population. Artificially intervening in the individual development of the child was required, for if not controlled properly, the 
individual character and dispositions could be potentially dangerous to the moral and spiritual future of the nation. ${ }^{28}$

Como tenho vindo a referir, o controlo das crianças diferentes em asilos e mais tarde em escolas foi uma medida de proteção, por um lado, de defesa social, por outro. É importante destacar que as primeiras instituições portuguesas que acolheram crianças com diferenças sensoriais, nomeadamente no campo da visão foram de carácter asilar. ${ }^{29}$ Instituições como as Misericórdias (1489), a Casa Pia (1789), o Instituto de Surdos-Mudos e Cegos (1823) - mais tarde incorporado na Casa Pia -, o Asilo de Nossa Senhora da Esperança de Castelo de Vide (1863) são exemplos dessa circunstância.

Só em 1888, com a fundação do Asilo-escola António Feliciano de Castilho podemos considerar que um plano escolar foi implementado. Considero plano escolar um sistema pedagógico estruturado em que uma instituição gere os discentes a partir de determinada idade até um limite etário superior acordado estatutariamente no início ou até os alunos atingirem um determinado ponto pretendido em termos de autonomia pedagógica e civil, recebendo instrução adequada e estruturada com vista à normalização dos seus conhecimentos por faixa etária e com destino ao serviço da comunidade.

Não obstante estes primeiros movimentos de integração pela escolaridade no nosso país, foi do Brasil que nos chegou o impulso à inauguração do modelo da escola para cegos francesa. Um dos grandes pedagogos da escola de Paris, M. Guadet (1795-1880), seu diretor entre 1840 e $1871^{30}$, grande impulsionador da colaboração entre escolas, recebeu um contacto do Brasil, o do Dr. José Francisco Xavier Sigaud (1796-1856) pai de Adèle Marie Louise Sigaud, que cegara jovem. ${ }^{31}$

Oftalmologista de D. Pedro II, Sigaud residia no Brasil, onde desenvolvia estudos diversos de investigação médica. Apresentava características ótimas para ser um promotor de novos projetos. Por um lado, sendo médico, dispunha do potencial de conhecimentos científicos para empreender semelhante projeto com credibilidade. Por outro lado, estava colocado numa posição socialmente privilegiada, tendo contactos com colegas residentes na Europa, designadamente em Paris. Finalmente, dado que era politicamente protegido

\footnotetext{
${ }_{28}$ «O governo da criança era uma resposta à incerteza da modernidade, mas também assumia uma estratégia cultural que expressava os medos de manter as qualidades de uma população civilizada. Intervir artificialmente no desenvolvimento individual da criança era requerido, porque se não fosse devidamente controlado, o carácter e disposições individuais poderiam ser potencialmente perigosos para a moral e o futuro espiritual da nação.» Tradução da autora a partir de Thomas Popkewitz, «Inventing the Modern Self and John Dewey: Modernities and the Travelling of Pragmatism in Education - An Introduction", in Inventing the Modern Self and John Dewey: Modernities and the Travelling of Pragmatism in Education, ed. Thomas Popkewitz (New York: Palgrave Macmillan, 2008), 19.

29 «A educação infantil pré-escolar, o ensino e educação das crianças deficientes mergulham as suas raízes mais profundas em estabelecimentos de carácter caritativo. A função de protecção ou de preservação primou durante longos anos sobre a função propriamente educativa", in Rogério Fernandes, História da Educação em Portugal (Lisboa, Livros Horizonte, 1988), 39.

${ }_{30}$ Zina Weygand, Vivre Sans Voir.

${ }^{31}$ Dicionário Histórico-Biográfico das Ciências da Saúde no Brasil (1832-1930). Online em http://www. dichistoriasaude.coc.fiocruz.br/iah/pt/verbetes/sigjoxav.htm (1 de Maio de 2018).
} 
por D. Pedro II, residente no Brasil, e muito possivelmente ligado à Maçonaria, integrava-se num perfil de idealismo científico e civilizacional. Dados os seus conhecimentos pessoais, recorreu a todos os processos de recuperação possíveis então conhecidos, terminando por assumir a cegueira definitiva da sua filha como diagnóstico. A ida a Paris, ao Instituto Haüy, levou o Dr. Sigaud a estudar metodologias e a conhecer instrumentos utilizados na educação, comunicação e socialização de cegos. Foi, pois, do Instituto Haüy que se encaminharam esses conhecimentos para o Brasil, e foi por esse motivo que foi criado 0 Imperial Instituto dos Meninos Cegos, hoje Instituto Benjamin Constant.

Ao vir para Portugal, depois da morte do pai, as filhas de Sigaud trouxeram uma pesada e poderosa herança. Ainda não havia em Portugal uma escola com condições e objetivos específicos para gerir condições de autonomia dos educandos à semelhança das escolas de Paris e do Rio de Janeiro suas conhecidas. Houve, assim, oportunidade para que fosse tomada a iniciativa de patronato de uma escola que gerasse educandos autónomos e integrados ${ }^{32}$. Finalmente, em 12 de março de 1888, no bairro em desenvolvimento de Campo de Ourique, em Lisboa, o Asilo-escola António Feliciano de Castilho foi instaurado pela Associação Promotora para o Ensino dos Cegos. 0 nome escolhido de António Feliciano de Castilho para a nova escola deveu-se a uma homenagem a um grande escritor, pedagogo, tradutor, político e ativista português, cego na sua primeira infância, que viveu entre 1800 e 1875. Teve vários cargos públicos na área da instrução e teve ainda o mérito de adaptar para língua portuguesa um sistema de aprendizagem de leitura e escrita conhecido por Método Repentino de Leitura, que durante anos fez concorrência ao Método João de Deus. Foi assim para inspiração dos seus alunos e homenagem deste mestre que o seu nome ficou associado a esta escola, já sua póstuma ${ }^{33}$. Quase em paralelo foram fundadas por Branco Rodrigues, em 1903 o Instituto S. Manuel no Porto e em 1913 o Instituto de Cegos Branco Rodrigues em S. João do Estoril. ${ }^{34}$

As grandes preocupações que encontrámos com a fundação destas escolas foram:

1. suprir uma ausência «Não existindo em Portugal nenhuma escola oficial para cegos»;

2. ser inovadores no ramo assistencial "Não basta, porém, ensinar e albergar os cegos na infância»;

3. ultrapassar o estado e outros projetos congéneres «tem este Asilo-Escola suprido tal falta da acção do Estado»;

4. integrar socialmente os cegos, para que a preparação para a sua vivência social e futura autonomia não encontrasse choques «Tornou-se, portanto, necessário pre-

\footnotetext{
${ }^{32}$ Erving Goffman, Stigma. Notes on the Management of Spoiled Identity (Londres: Penguin Books, 1990).

${ }^{33}$ Justino de Magalhães, Dicionário de Educadores Portugueses, 198 e seguintes.

${ }^{34}$ Isidro da Eira Rodrigues, "Os deficientes visuais portugueses: sua acessibilidade à educação e à cultura desde o advento do século XX ao dealbar do terceiro milénio", in O Braille em Portugal - Exposição comemorativa do bicentenário de Louis Braille, coord. Isidro da Eira Rodrigues, Ana Isabel Líbano Monteiro (Lisboa: Biblioteca Nacional de Portugal, 2009).
} 
parar na sociedade um ambiente favorável à aceitação dos cegos. A aproximação dos indivíduos cegos produzia uma impressão compungente de insanável tristeza, como que a sugestão dum irremediável infortúnio»;

5. solucionar os problemas anteriores com um projeto inovador e bem alicerçado na experiência da observação e do trato diário «fazer constatar que a cegueira em nada afecta as disposições de convívio, as vantagens de sociabilidade»;

6. elevar, pela lucidez, conhecimento e mérito, os promotores e apoiantes do projeto "O Asilo-Escola António Feliciano de Castilho vem, pois, praticamente demonstrando que, tal como no estrangeiro, pode, entre nós, uma pessoa cega mas instruída tornar-se útil e independente e, até mesmo, notável pela cultura da música, e pelo fulgor de um espírito de escol». ${ }^{35}$

Para termos uma ideia geral do panorama educativo português à época, 0 analfabetismo era dado como sendo de 78\% em 1878 e 76\% em 1890. Qualquer gesto educativo já seria, portanto, frutuoso. Mais ainda tratando-se de uma questão de equidade social, de integração e de coeducação. Em termos de educação especial, Portugal manteria 0 mesmo ritmo educativo nas mesmas instituições. Mais tarde continuaria a bater-se com o conservadorismo aportado pelo Estado Novo (1928-1974), circunstância em que surge o nosso caso de estudo, no foro do ensino privado, possibilitando um sistema alternativo, como seguidamente se apresenta.

\section{A Liga Portuguesa da Profilaxia da Cegueira: uma escola fora do sistema}

Nos anos 50 do século XX, Portugal encontrava-se sob um regime centralizador, o que gerava uma comunidade de profissionais que estavam, por ideologias opostas à do regime vigente, impedidos de exercer a sua profissão nos serviços públicos portugueses. É dessa comunidade que nos irão chegar, em projetos privados, várias iniciativas arrojadas e inovadoras, muitas de carácter experimental.

O início do grande trabalho multidisciplinar que originaria o Centro Infantil Helen Keller encontra-se na dinâmica internacional do oftalmologista português Mário Moutinho, médico militar. Em 1922 encontrava-se em Haia num Congresso de Oftalmologia em que foi criada a Liga Internacional de Profilaxia da Cegueira, e foi-lhe dada a incumbência de criar a delegação portuguesa daquela entidade ${ }^{36}$. Já então 0 assolavam preocupações sociais e pedagógicas. Em 1936 fundou a Liga Portuguesa de Profilaxia da Cegueira. Com o apoio de seu filho, o médico oftalmologista Mário Moutinho, veio a angariar junto do Rotary Club de Lisboa os apoios necessários para o desenvolvimento desta nova entidade.

Estatutariamente, a finalidade da Liga Internacional de Profilaxia da Cegueira consistia em «empreender o estudo das causas diretas ou indiretas da cegueira ou enfraquecimen-

\footnotetext{
35 «Estatutos da Liga Portuguesa de Profilaxia da Cegueira e Reabilitação de Inferioriados Visuais», Diário do Governo no. 275, 3ㄹ série, 26 de Novembro de 1957.

${ }^{36}$ Maria Eduarda Dias, Ver, Não Ver e Conviver (Lisboa: INR, 1995).
} 
to da visão " ${ }^{37}$, mas também promover medidas para o desaparecimento dessas causas, reeducar os inferiorizados visuais, abrindo caminho para a sua integração laboral e social e divulgar os conhecimentos e técnicas obtidos pela própria Liga. Nesse sentido, o projeto expandiu para a fundação de um Grupo de Estudos, de que nasceu a Clínica de Reeducação de Amblíopes. A associação a pedagogos e psiquiatras como João dos Santos e Maria Amália Borges daria uma ênfase psicopedagógica ao projeto. Em 1955 era, assim, fundado o Centro de Reeducação de Diminuídos Visuais ou Centro Infantil de Reeducação de Inferiorizados Visuais ${ }^{38}$. Em março de 1956, a convite da Liga Portuguesa da Profilaxia da Cegueira, Rotary Club e Fundação Calouste Gulbenkian, Helen Keller foi convidada para vir a Portugal e permitiu que o seu nome fosse associado ao Centro.

A importância da criação da Liga Portuguesa da Profilaxia da Cegueira no desenvolvimento do binómio pedagógico natureza-sentidos em Portugal passou por três fatores:

- A interação entre pedagogia e medicina;

- A fundação de um centro de ensino para crianças amblíopes que, mais tarde, daria origem a uma escola integrada (alunos cegos, amblíopes e normovisuais), em regime de coeducação;

- O desenvolvimento de um movimento de educação cooperativa e integrada, suportada teoricamente em António Sérgio e em Celéstin Freinet.

Foi a partir deste gesto inovador, e da participação no mesmo, de vários profissionais que, por impedimentos políticos, não podiam exercer no ensino público - nomeadamente Henrique Moutinho, João dos Santos, Maria Amália Borges, mais tarde Sérgio Niza - que o futuro Centro Infantil Helen Keller se foi inspirando em várias metodologias como a imprensa, o jornal de parede, o regime cooperativo de alunos, a ligação à sociedade e ao ambiente, a procura livre da escrita e da arte, a correspondência escolar e a produção de publicações feitas por alunos, em cujas temáticas as explorações no terreno, as visitas de estudo, o património construído e natural e a natureza - fauna e flora - dominavam. Era tempo de procurar um local adequado para desenvolvimento desses interesses que os alunos refletiam nos seus trabalhos e os professores procuravam potenciar, até pela riqueza que aportavam à diversidade sensorial existente entre os vários alunos do então Centro Infantil Helen Keller.

\section{O centro Helen Keller e o parque natural de Monsanto As instalações}

É necessário, para compreendermos a relevância deste desejo de instalações adequadas, fazer um pequeno historial das várias instalações da escola e suas dificuldades

\footnotetext{
${ }^{37}$ Revisão dos «Estatutos da Liga Portuguesa de Profilaxia da Cegueira e Reabilitação de Inferiorizados Visuais", aprovados por despacho do Subsecretário da Assistência, Diário do Governo no. 275, $3^{\text {an }}$ série, de 26 de Novembro de 1957.

${ }^{38}$ Henrique Moutinho, João dos Santos, "Aspectos Médico Psicológicos e Sociais da Vida dos Cegos", Revista Portuguesa de Oftalmologia Social. Strabismus (1964-1965): 20.
} 
iniciais. De acordo com o testemunho de Maria Amália Borges, em 1955-56 o Centro de Reabilitação de Inferiorizados Visuais esteve em funções no Colégio de Reeducação, atual Colégio Claparède. Em segundo lugar, no ano de 1958-1959 a classe de amblíopes passou para as instalações clínicas utilizadas pelo Dr. Henrique Moutinho no Asilo-escola António Feliciano de Castilho. Em 1959 foi fundada a Fundação Raquel e Martin Sain, onde foi integrada a Classe de Amblíopes do Centro de Recuperação da Liga de Profilaxia da Cegueira, com diversas valências, primárias e secundárias, artísticas e de educação física. Deste modo, nos anos de 1959-60 e 1960-61, a sede do Centro de Reabilitação de Inferiorizados Visuais da Liga Portuguesa de Profilaxia da Cegueira e os seus projetos funcionaram em edifícios daquela Fundação, na Avenida Óscar Monteiro Torres e na Avenida D. Carlos. Apenas as aulas de ginástica funcionavam em outro edifício, nas instalações de H. Vaultier, uma empresa vizinha. Por divergências de gestão optou-se por mudar os postos escolares entretanto criados para duas salas de uma escola oficial de Lisboa, na rua Teixeira de Pascoais. A secção liceal passou para casa da própria Maria Amália Borges, na Rua Maria.

No ano de 1961-1962, e graças a apoios da Misericórdia de Lisboa e da Fundação Calouste Gulbenkian, foi alugada a sede da Rua José Estevão, 133, r/c. Nesse ano os funcionários do Centro eram 15 e os alunos 55. Em agosto de 1963 Maria Amália Borges partiria para o exílio político no Canadá. Em 1966 o Centro Infantil Helen Keller passou para as instalações do Jardim Constantino, as sétimas da instituição e em muito más condições. Como recurso, e por intermédio de um dos seus diretores, o Centro mudou-se então para a Rua Monte Olivete, de 1970 até $1973 .{ }^{39}$

Toda esta sequência de instalações inadequadas causava muitos transtornos ao programa pedagógico da instituição. Em curtas metragens que consultámos são entrevistados professores do Centro no meio de barulho de obras e de rua, Não havia jardim. As visitas e estímulos de fora da sala de aula tinham todos que se basear em visitas de exterior e nem sempre havia fundos para o desenvolvimento dessas atividades, muitas vezes propostas pelos alunos em assembleia própria. Na revista escolar $A$ Pérola, a natureza e as visitas de estudo constituíam a maior parte do interesse dos alunos, nas suas redações e desenhos ${ }^{40}$. Mas as condições não estavam ainda criadas para o melhor usufruto destes interesses.

Finalmente, em 1968, na sequência de uma reunião de pais em que a questão das instalações tinha sido declarada como premente, o Dr. Artur Anselmo ${ }^{41}$, pai de um aluno do Centro e seu futuro Presidente, propôs-se tentar tratar do assunto, informando-se das possibilidades de instalações mais adequadas e definitivas junto da Câmara Municipal de Lisboa. É daí que vem o esforço da mudança para o Restelo, para as instalações

\footnotetext{
${ }^{39}$ Entrevista à Diretora Pedagógica do Centro Helen Keller Dra. Maria Eduarda Dias, realizada por Maria Romeiras Amado, Lisboa, 24 de Outubro de 2016.

${ }^{40}$ Arquivo Histórico do Centro Helen Keller, Jornal A Pérola (1966-1975).

${ }^{41}$ Entrevista ao antigo Presidente da Direção do Centro Infantil Helen Keller, Prof. Doutor Artur Anselmo realizada por Maria Romeiras Amado, Lisboa, 11 de Janeiro de 2017.
} 
definitivas do Centro Helen Keller, cedidas por um preço razoável pela Câmara Municipal de Lisboa. Em 1973 fez-se a mudança de todas as estruturas da escola para barracões pré-fabricados cedidos pelo Ministério da Educação.

Hoje, no Restelo, o Centro Helen Keller tem as suas estruturas administrativas, as suas aulas, as suas terapias, as suas atividades de educação física, a sua quinta pedagógica, horta e jardim em $11.000 \mathrm{~m}^{2}$ de terreno. ${ }^{42}$ Os seus agora 500 alunos disfrutam de uma área natural privilegiada e rica em potencial pedagógico, sobretudo num tempo em que a natureza se encontra tão dependente de uma relação produtiva com o homem. Sensorialmente, o espaço é aproveitado quer do ponto de vista da orientação e mobilidade, quer do ponto de vista do convívio e de alguma liberdade em meio urbano. Como se processou o enriquecimento do parque escolar e em que medida esse gesto foi relevante para a pedagogia integrada do nosso caso de estudo é o assunto que abordarei de seguida.

\section{O potencial pedagógico natural: temas, aulas, arte, escrita}

The concept of biophilia is based on the understanding that people need contact with the natural environment in the same way they need contact with other people as a necessity for their development. This need applies to everyone, including children with special educational needs. ${ }^{43}$

Em 1973, o acordo com a Câmara Municipal de Lisboa estava concluído e as crianças foram deslocadas para as novas instalações provisórias, nos antigos campos de trigo do Restelo, terreno basáltico completamente por construir. 0 empoderamento espacial foi poderoso: aproveitando os materiais pré-fabricados de início, para salas de aulas e estruturas de apoio, começaram desde logo a ser aproveitados os espaços naturais para recreio, jardim e horta, quinta pedagógica, meio de recolha de materiais de trabalho em sala de aula, aulas de exterior... A dimensão do terreno e as suas características tornavam o processo dinâmico e o entusiasmo dos alunos real. Há inúmeras redações n'A Pérola sobre estes projetos, assim como documentação fotográfica e filmada sobre a mudança e implementação de dinâmicas pedagógicas em plena natureza. É de relevo mencionar que mais de $80 \%$ das redações impressas no jornal escolar tinham a natureza como tema.

No Restelo, os alunos podiam ter a liberdade de ver, sentir, tocar, cheirar as plantas e legumes provenientes dos seus trabalhos no jardim e na horta, assim como interagir com os animais domesticados e habitantes da quinta pedagógica, novos companheiros do seu espaço de recreio. $O$ espaço e a sua organização em diversos recursos pedagógicos e recreativos mediavam agora a familiarização de alunos cegos ou com baixa visão com

\footnotetext{
${ }^{42}$ Centro Helen Keller - Instituição Particular de Solidariedade Social, http://www.centrohelenkeller.pt (12 de Outubro de 2018).

${ }^{43}$ "O conceito de biofilia é baseado na compreensão da necessidade de contato das pessoas com o ambiente natural, da mesma forma em que necessitam de contatar com outras pessoas, como uma necessidade para 0 seu desenvolvimento. Esta necessidade aplica-se a todas as pessoas, incluindo crianças com necessidades especiais." Tradução da autora com base em Green inclusion: Biophilia as a necessity, https://www. childrenandnature.org/research/environmental-education-promotes-the-inclusion-of-children-with-special-needsand-addresses-their-biophilic-needs/ (10 de Agosto de 2018).
} 
algumas realidades que em meio urbano seriam de difícil acesso. Por outro lado, os intensos sons do centro da cidade e das obras que os tinham acompanhado nalgumas das instalações tinham desaparecido, dando lugar a intensidade de alternância de silêncios e sons específicos, suaves ou altos, desde as folhas das árvores batidas pelo vento ao canto intenso dos pavões. 0 domínio do espaço era assim facilitado pelos sons que localizavam progressivamente os alunos menos baseados na visão numa coreografia de pontos de referência sonoros e táteis.

Quanto aos professores e pedagogos, tinham agora à sua disposição materiais e temas novos e abundantes. Descobrir e partilhar eram as palavras-chave. 0 cuidado da quintinha e dos outros animais domésticos, tal como a responsabilidade pelo jardim e horta eram levados bastante a sério pela comunidade de alunos e processos como o uso da culinária que resultam em partilha eram bastante bem-vindos e encontram-se muito documentados em registos escritos dos alunos e em materiais fotográficos da época da mudança de instalações ou pouco posterior.

Os projetos de arte, que as técnicas Freinet sempre tinham incentivado, e que tinham sido apoiados desde o início da escola pela artista Cecília Menano, tinham agora materiais diversos para reaproveitar nas suas produções: paus, pedras, penas, folhas e outros materiais de ar livre aproximaram a natureza da arte.

As técnicas Freinet e as teorias da Escola Moderna que se Ihes seguiram no Centro Helen Keller eram agora mais fluidas e mais fáceis de desenvolver. Nenhum estudante ficava para trás em termos de aprendizagem, porque a riqueza de elementos a estudar era tão diversa que, por muito que as suas diferenças sensoriais fossem marcantes, havia sempre opções para contornar a aquisição de informação quer em termos teóricos quer - agora reforçados - em termos práticos. Podemos considerar que eram métodos precursores do atual sistema Forest $\mathrm{Schoo}^{44}$, em que as aulas de exterior são bastante incentivadas.

Por outro lado, nas minhas entrevistas com antigos alunos do Centro, as memórias dos alunos, tanto cegos quanto normovisuais ${ }^{45}$ foram bastante positivas e em relação ao meio escolar em que tinham sido integrados e as suas recordações eram bastante descritivas, quer do recreio-espaço, quer do recreio enquanto local para atividades de ginástica e jogos de conjunto. A sua perceção do espaço era bem definida e as várias áreas em que o mesmo era organizado relacionavam-se naturalmente e tinham referentes naturais como parte integrante da sua secção da escola. As rotinas da escola - tempo - organizava-se assim em torno do espaço largo e cheio de detalhes de flora e acolhedor da fauna assumida como conveniente para convívio com os alunos e para sua responsabilização e educação.

\footnotetext{
${ }^{44}$ What is different about Forest School? Creating a space for an alternative pedagogy, https://www. childrenandnature.org/research/the-divergence-and-freedoms-inherent-in-forest-school-may-contribute-to-thewell-being-of-participants/ (20 de Agosto de 2018).

${ }^{45}$ Entrevista à antiga aluna do Centro Helen Keller Dra. Susana Cordeiro, realizada por Maria Romeiras Amado, Oeiras, 8 de Fevereiro de 2017 e entrevista ao antigo aluno do Centro Helen Keller Dr. Francisco Malta Romeiras, realizada por Maria Romeiras Amado, Lisboa, 30 de Março de 2017.
} 
Os espaços previstos para educação física eram diversos, desde zonas suficientemente abertas para a promoção de jogos no recreio até aos campos de jogos que têm vindo a ser desenvolvidos até aos nossos dias. Neles foram e são praticados desportos adaptados aos vários níveis de sentidos, seja pelo uso de bolas com guizos - prática bastante regular em escolas integradas desde o século XIX - até à estrutura de campos de Goalball ${ }^{46}$ outro ponto central de organização social dos alunos, desta vez tendo os alunos cegos como centro da atividade.

Em relação às visitas de campos, elas eram praticadas desde a fundação da escola, sobretudo pela escassez de meios para atividades de exterior nas primeiras instalações. Mas continuaram mesmo depois da mudança para as instalações do Restelo, sendo que encontramos cerca de uma visita de exterior por mês no quadro de atividades dos alunos do Centro Helen Keller durante o ano de 2017.

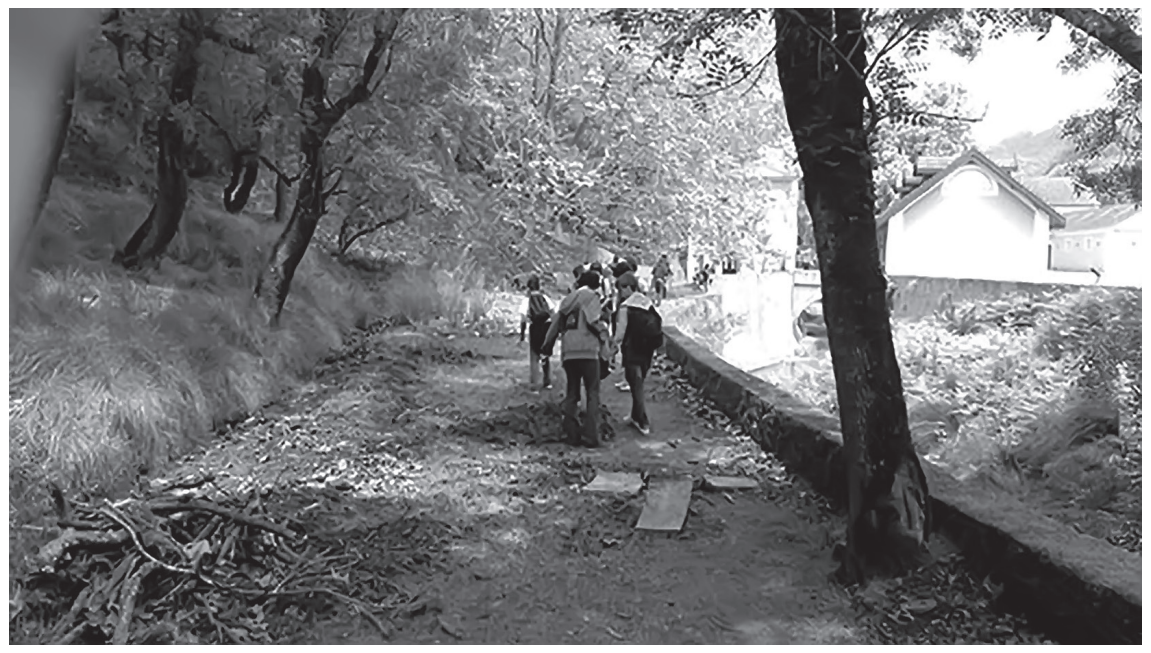

Figura 3. Visita de campo à Tapada de Mafra, 2017.

As visitas de campo e seus relatos permitiam a exploração dos temas, com grande incidência em motivos naturais (Aquário Vasco da Gama, Oceanário, Tapada de Mafra, Quintas Pedagógicas...). O trabalho pedagógico anterior, de preparação da visita, e posterior, de aproveitamento dos temas, da experiência e dos materiais, permitiam trabalhos de conjunto em que os vários anos desenvolviam diversas competências, dentro de um espírito cooperativo que se integrava no espírito original da escola. Ainda dos relatos dos antigos alunos e de uma das suas diretoras pedagógicas ${ }^{47}$ nos chega a mensagem da

\footnotetext{
${ }^{46}$ Goalball, https://www.paralympic.org/goalball (25 de Outubro de 2018).

${ }^{47}$ Entrevista à Diretora pedagógica do Centro Helen Keller Dra. Ana Lúcia Pelarigo, realizada por Maria Romeiras Amado, Lisboa, 30 de Novembro de 2017.
} 
colaboração dos alunos normovisuais e cegos ou amblíopes em situações em que fosse necessário conduzir os colegas e descrever algum detalhe do passeio que não lhes fosse imediatamente percetível.

\section{A divulgação: correspondência, intercâmbio, revistas escolares, redes sociais}

Sendo o nosso caso de estudo fundado com base em técnicas Freinet e em vivências cooperativas, o contacto com o outro dentro e fora da escola é de grande importância. Vários projetos foram assim desenvolvidos desde a sua fundação em 1955 até aos nossos dias para valorizar o respeito e o contacto correto com o outro, promovendo os valores de socialização, de respeito e de democracia. Em primeiro lugar, há que destacar que no início a imprensa foi um projeto fundamental para a pequena comunidade escolar. A imprensa começou por ser apenas feita a tinta, mas mais tarde pode também ser feita a Braille e relevo. Assim, todos os alunos foram integrados nesta sua tão especial relação com a escrita. As composições, recados, pensamentos, redações, eram escritas pelos alunos em colaboração com os professores e muitos deles, que chegaram até nós têm temas da natureza. E o conteúdo era dominado pela forma, dado que desde os anos 50 os processos de impressão usados eram abertos à participação de todas as crianças incluídas no projeto, dada a progressão técnica que permitia a execução de relevos.

O outro com que me correspondo é assim diverso como os meus temas. Seja nas minhas redações impressas, seja na correspondência interescolar - outra das marcas das técnicas Freinet - o outro está sempre presente na minha reinvenção do conceito de humanidade, de diversidade. Numa escola cuja prioridade era a integração, este é um fator particularmente importante.

A divulgação dos resultados das vivências e das experiências em revistas impressas ou editadas e, nos tempos mais atuais, em formato digital, por todos os alunos, é uma parte integrante do seu dia-a-dia e as revistas que se foram sucedendo, assim como o website da escola e a sua página de Facebook são meios intensos de divulgação de todas as atividades que temos vindo a descrever.

Finalmente, e dada a proximidade da educação artística ao espírito da escola, as produções dos alunos foram sempre sendo expostas e partilhadas por todos, sendo esses trabalhos também divulgados, em ocasiões de abertura da escola à comunidade em datas de socialização como o Natal, o Arraial de Final de Ano, o Dia da Árvore, os dias da Mãe e do Pai.

\section{Natureza e o futuro num projeto pedagógico experimental}

Na contemporaneidade desta escola, a mensagem primordial é a de preparar o futuro. Assim, a natureza surge numa perspetiva aliada, numa empatia de responsabilidade. Preparar o futuro tem duas linhas de ação pedagógica: sensibilização e ação. Os três «r»: reduzir, reutilizar e reciclar são aplicados no quotidiano, quer na integração da arte e dos sentidos em projetos pedagógicos da contemporaneidade, feitos com materiais reciclados, quer na criação em sala de aula de competências e responsabilidades do coletivo com 
propósitos cívicos, Usufruir socialmente dos resultados é a parte final do processo, em relatórios de reciclagem, em reuniões cooperativas de alunos, em produções literárias, poéticas e artísticas, divulgadas em eventos públicos da escola ou em reportagens em jornais escolares ou redes sociais, nas quais o Centro Helen Keller é bastante ativo.

Com as influências teóricas mencionadas e com o seu percurso de procura do espaço ideal para desenvolvimento das mesmas dentro de um quadro de integração de diversidade a rentabilizar pela criatividade e diversidade do próprio meio natural concluímos que o Centro Helen Keller é um ótimo referente contemporâneo para desenvolvimento de experimentações dentro do binómio pedagógico espaço sensorial/ diversidade sensorial. As mais recentes atividades e experiências, como os concursos literários de temática relacionada com a natureza, nomeadamente com o Dia da Árvore ou outras datas de relevo na vida da escola, as propostas de criações artísticas com materiais reciclados como a construção de árvores de natais diferentes - em que a possibilidade de trabalhar com materiais reciclados é positiva também para os alunos que utilizam mais o tato que a visão, celebrando a possibilidade da sua intensa participação cívica. Finalmente, a associação da escola ao projeto português Ecoescolas ${ }^{48}$ dinamizou de novo as iniciais comissões de alunos dos primeiros tempos do Centro Infantil Helen Keller em temática de interesse ecológico e cívico.
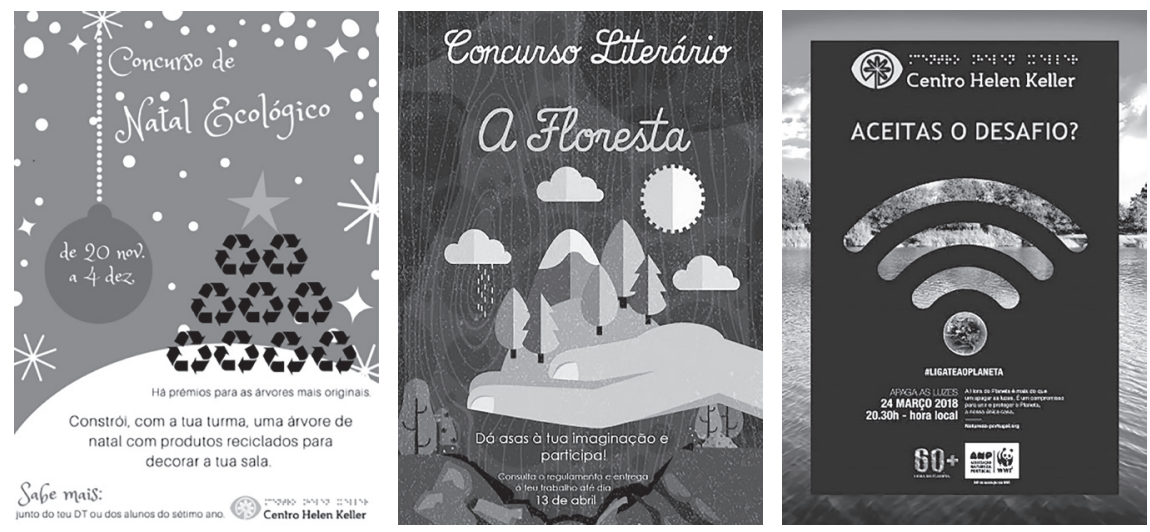

Figura 4. Iniciativas de temática natural e ecológico desenvolvidas pelo Centro Helen Keller durante 0 ano de 2017.

Outra área de inovação é a de apoio à terapia, em concreto, a terapia apoiada por animais, já não tanto apenas pelos fatores de conhecimento e convívio que eram desenvolvidos e fomentados desde o início da escola, mas pela introdução de um animal preparado, treinado, um cão de terapia, que acompanha a equipa de ensino especial, designadamente a sua responsável, nas sessões de terapia, aulas, dinamizações de sessões académi-

${ }^{48}$ Quem Somos - Eco-Escolas, https://ecoescolas.abae.pt/sobre/quem-somos/ acedido (25 de Outubro de 2018). 
cas e de brincadeiras no recreio. Os alunos parecem responder bastante bem a mais este estímulo, em particular alunos com novos requisitos de apoio sensorial como os alunos no espectro do autismo a que a escola alargou as suas inscrições. O labrador Verdi é assim um novo elemento cujo contacto físico e emocional com os alunos é de grande proveito para sessões de leitura, terapia e interação em geral. Novos projetos que acompanham novos tempos, mantendo a Natureza, os seus elementos de fauna e de flora, a responsabilidade pela sua preservação e a divulgação coletiva dos seus objetivos como primordial.

\title{
Conclusão
}

\begin{abstract}
A historicidade do corpo faz com que haja modificações e nossos gestos adquiram significados novos mediante as experiências que vão ocorrendo. E é através desses gestos que somos capazes de expressar muitos desses símbolos e esconder outros, formando, portanto, a linguagem do corpo; o corpo está sempre se reorganizando. E por possuir espacialidade e temporalidade próprias, cada corpo vai adquirindo percepções de acordo com o mundo que lhe é específico. ${ }^{49}$
\end{abstract}

Tendo em conta o que fui descrevendo com base na história do Centro Helen Keller e na sua atividade atual, podemos inferir que a influência de diversos pedagogos no gesto integrador desta escola foi fundamental para a sua eficiente aceitação da diversidade e dos seus processos de aprendizagem criativos e cooperativos. Pestalozzi, com a introdução da lousa na sala de aula, e com ela modificando a postura corporal dos alunos perante a materialidade, como Froebel com a defesa da integração escola-natureza através do jogo, da psicomotricidade e da jardinagem ou ainda a teorização de Montessori da autodeterminação infantil e utilização de material didático lúdico e variado em espaços flexíveis e estimulantes como os espaços naturais foram alguns dos teóricos que valorizaram a natureza e a sua interação com o corpo do aluno na educação. De realçar ainda a importância dada por Decroly à relação da criança com a dinâmica estimulante da natureza, fonte de saúde e de conhecimento e, finalmente, de Celéstin Freinet com as suas propostas de escola fora da escola e de partilha e de comunidade cooperativa.

A conclusão desta breve viagem pelas possibilidades pedagógicas deste encontro dos sentidos de diversos alunos pelas diversas potencialidades da natureza envolvente a um meio escolar conduz-nos a novas interrogações e potencialidades da integração de alunos diferentes no meio da natureza, um meio de novidades, usufruto e aprendizagem de todos e para todos, em que a criatividade se impõe e a ligação da natureza humana ao meio natural é uma realidade de desenvolvimento pedagógico e não apenas um espaço inativo. É desse gesto de produtividade pedagógica e desse contato sensorial privilegiado e individualmente rico que cresce o sentir cooperativo e socializante da comunidade escolar, potência integradora a explorar em permanência.

Recapitulando toda a divulgação de resultados elaborada pelos próprios alunos e pelos relatórios sociais da escola, a lista de actividades escolares - dentro e fora da escola relacionadas com a natureza/animais/ecologia durante o passado ano letivo de 2017/2018

${ }^{49}$ Maria Isabel Brandão de Souza Mendes e Terezinha Petrucia da Nóbrega, "Corpo, natureza e cultura», 129. 
manifesta um grande investimento: por um lado os alunos referem continuamente estes três temas como centrais às suas atividades durante o tempo escolar; por outro lado realço a ocorrência de pelo menos duas atividades relacionadas com a natureza por mês (aulas ao ar livre e suas produções e temas posteriores, visitas de estudo e seu aproveitamento para trabalhos em arte e escrita, serviço comunitário dedicado a projetos ecológicos com diversas atividades decorrentes deste tema em termos criativos e de divulgação social). Os 500 alunos atuais, dos quais $20 \%$ são deficientes, assumem um papel bastante ativo nestas ocorrências pedagógicas e a sua interação é notável.

A Natureza assumiu assim, desde muito cedo, um papel muito importante no reconhecimento sensorial e no estudo do mundo para os alunos do Centro Helen Keller: contribuíu para a cooperação entre os alunos cegos, amblíopes e normovisuais, assim como mais tarde a crianças com diferentes patologias que foram sendo admitidas e incorporadas na grande comunidade integradora que é esta escola. Para todos eles, os projetos associados à natureza foram uma porta para uma mais eficiente interação social, além de gerar meios de conhecimento criativos e inovadores.

Desta forma, a ontologia destes estudantes e as suas narrativas diárias sobre a escola como comunidade surgem exponenciadas pelo ambiente natural envolvente às instalações do parque florestal de Monsanto, que permitiu desenvolver desejos pedagógicos que se encontravam desde o início da escola em potência. E as sugestões dos vários pedagogos experimentalistas que orientaram a escola desde o seu início tal como a potência dos fatores som, cheiro, som, textura e visão/descrição dos elementos naturais geraram um artesanato paciente de desenvolvimento não só no trabalho pedagógico, mas também nas competências sociais e na segurança e competências individuais de cada um dos alunos, independentemente das suas capacidades sensoriais que, sem dúvida, ampliou a competência integradora do Centro Helen Keller. 